\title{
Equality and equity: An emerging government policy in northern ireland
}

Colin Knox, Joanne Hughes

Graduate School of Public Policy

\section{Abstract}

A series of equality and equity measures has been introduced by the British Government to tackle the seemingly intractable problems of Northern Ireland. These measures represent a range of initiatives in the areas of social need, fair employment, education reform and community relations. The implementation of the community relations programme is considered in some detail as a case study in improving equality and equity in Northern Ireland. Qualitative data from community relations officers, charged with implementing the policy, are examined in the light of problems encountered with the programme. The influences on delivering community relations, as one component of this comprehensive thrust to attain equality and equity, are also considered using an explanatory model. The article concludes that changes in attitudes and behaviour between the two communities are occurring, albeit slowly, promoted by the measures described. (C) 1994, Taylor \& Francis Group, LLC. All rights reserved.

$\begin{array}{ll}\begin{array}{l}\text { Originallanguage } \\ \text { Pages (from-to) }\end{array} & \text { English } \\ \text { Number of pages } & 207-225 \\ \text { Journal } & 19 \\ \text { Volume } & \text { Journal of Ethnic and Migration } \\ \text { Issue number } & 20 \\ \text { State } & 2 \\ \end{array}$

Knox, C., \& Hughes, J. (1994). Equality and equity: An emerging government policy in northern ireland. Journal of Ethnic and Migration Studies, 20(2), 207-225. DOI: $\underline{10.1080 / 1369183 X .1994 .9976420}$ 